\title{
BMJ Open The UALE project: a cross-sectional approach for trends in HIV/STI prevalence among key populations attending STI clinics in Guatemala
}

\author{
Juan Ignacio García, ${ }^{1,2,3}$ Meritxell Sabidó, ${ }^{4,5}$ Mikhail Nikiforov, ${ }^{1}$ Adriana Smith, ${ }^{1}$ \\ Gabriela Hernández, ${ }^{1}$ Rudy Ortiz, ${ }^{1}$ Luis Ardani, ${ }^{1}$ Alba Cajas, ${ }^{1}$ Elsy Camey, ${ }^{1}$ \\ Jordi B Torrelles, ${ }^{6}$ Shu-Hua Wang, ${ }^{7}$ Colin N J Campbell, ${ }^{8}$ Cinta Folch, ${ }^{2,5}$ \\ Jordi Casabona, ${ }^{1,2,5,9}$ on behalf of the UALE Study Group
}

To cite: García Jl, Sabidó M, Nikiforov M, et al. The UALE project: a cross-sectional approach for trends in HIV/ STI prevalence among key populations attending STI clinics in Guatemala. BMJ Open 2018;8:e022632. doi:10.1136/ bmjopen-2018-022632

- Prepublication history for this paper is available online. To view these files, please visit the journal online (http://dx.doi. org/10.1136/bmjopen-2018022632).

Received 6 March 2018 Revised 19 June 2018 Accepted 23 July 2018

Check for updates

(C) Author(s) (or their employer(s)) 2018. Re-use permitted under CC BY-NC. No commercial re-use. See rights and permissions. Published by BMJ.

For numbered affiliations see end of article.

Correspondence to Mr. Juan Ignacio García; areoso14@yahoo.es

\section{ABSTRACT}

Objective To describe and compare trends in prevalence, sexual behaviour and HIV transmission knowledge data related to sexually transmitted infections (STI) and HIV in patients attending three STI clinics over an 8-year period in Escuintla Department, Guatemala.

Methods STI clinic attendees were classified into transmission groups as follows: female sex workers (FSW), men who have sex with men (MSM) and 'high-risk heterosexuals' (HRH). Annual cross-sectional analysis and multivariable Poisson regression adjusted for sociodemographic variables were used for prevalence comparisons and adjusted prevalence trends for HIV/STI outcomes and used for adjusted trends in proportions in sexual behaviour and HIV transmission knowledge outcomes. Endocervical swabs were obtained to detect trichomonas, chlamydia and neisseria infections.

Serologies for syphilis and HIV were performed using rapid tests. For reactive HIV samples, positivity was confirmed by an ELISA. All reactive syphilis samples were further confirmed for diagnosis of active syphilis disease.

Results From a total of 4027 clinic attendees, 3213 (79.78\%) were FSW, 229 (5.69\%) were MSM and 585 (14.53\%) were HRH. The proportion of FSW, MSM and HRH who had a single visit was $56.42 \%, 57.23 \%$ and $91.10 \%$, respectively. Overall, HIV prevalence was $2.10 \%$ in FSW, $8.17 \%$ in MSM and $4.12 \%$ in HRH. Prevalence trends in HIV and syphilis decreased in FSW. Prevalence trends in gonorrhoea did not decrease over time neither in FSW nor in HRH. Chlamydia and trichomonas infections in $\mathrm{HRH}$ showed an increase prevalence trend. In FSW, trends in condom use in last sexual intercourse with regular and occasional clients were above $93 \%$.

Conclusions FSW show a decreasing trend in HIV, syphilis and chlamydia prevalence. Gonorrhoea prevalence in FSW and HRH did not decrease over time. HRH is a hard to engage population with low follow-up rates and high potential to act as a bridge population.

\section{INTRODUCTION}

Despite continuous efforts for prevention and control of sexually transmitted infections

\section{Strengths and limitations of this study}

- This is one of the large datasets collected in Central America in HIV/sexually transmitted infections (STI) prevalence in key populations attending sentinel STI clinics.

- HIV/STI trends are calculated from an 8-year study period using prevalence ratios with Poisson regression analysis rather than odds ratios.

- The cross-sectional approach used to analyse data compared with a cohort study may be less powerful regarding the strength of the evidence of associations found.

- Selection bias issues and missing values for some variables may affect interpretation and generalisability of some results.

(STI), these still pose a high burden of disease in both low-income and high-income countries. ${ }^{12}$ Guatemala is one of the Central American countries with higher prevalence of STI and HIV. ${ }^{34}$ Of the estimated 55000 people living with HIV, approximately less than half of them have been diagnosed. ${ }^{5}$ Guatemala has a concentrated HIV epidemic driven by sexual transmission with high prevalence in core groups such as female sex workers (FSW) and men who have sex with men (MSM), at $5 \%$ and $11 \%$, respectively. ${ }^{67}$ FSW and MSM are classified as core groups because of social and biological factors, and thus, are targeted for effective STI and HIV prevention and control interventions. ${ }^{8}$

Multicomponent packages for STI and HIV prevention have been shown to be effective when properly designed and delivered at individual and community levels. However, strong evidence from intervention evaluations is crucial, and accurate surveillance systems are needed. ${ }^{9}{ }^{10}$ Patients attending 
STI clinics provide valuable HIV and STI biological and behavioural data for surveillance purposes; therefore, surveillance systems in STI clinics should be strengthened and integrated into health information systems to better provide nationwide insights into transmission dynamics of HIV and STI. ${ }^{11}$

The UALE project (UALE means 'health' in Latin) started in 2005 as an intervention for STI and HIV prevention and care originally addressed to FSW in Guatemala. ${ }^{12}$ This project was designed with the following principles: (1) prevention and treatment of STI as a strategy to prevent HIV infection, (2) integrated biological and behavioural surveillance of HIV/STI and (3) effective integrated HIV/STI management and care. It included three STI clinics located in Escuintla's Department, which has one of the highest prevalence of HIV and STI among the 22 Departments of Guatemala. ${ }^{6}$ Contributing factors of high HIV and STI prevalence are its position along a major thoroughfare for migration and trafficking and the widespread sex work industry due, in part, to the influx of seasonal labourers during the sugar cane harvest.

The UALE project includes three main components: biomedical, behavioural and structural, as previously described. The biomedical component provides clinical capacity for early diagnosis, treatment and follow-up for STI offering HIV and STI care access to all populations seeking sexual and reproductive health. The behavioural component relies on communication for behavioural change; it consists of community-based activities to promote safer sexual practices, including proper condom use, improved negotiation skills, partner notification strategies and sexual and reproductive health empowerment activities addressing issues related to stigma and discrimination. The structural component aims to decrease the criminalisation and stigmatisation of sex work through sensitisation and collaboration with the owners of commercial sex establishments, the police and with governmental organisations and non-governmental organisations (NGO) for advocacy meetings and community health promotion.

The aims of this study were the following: (A) describe sociodemographic characteristics of patients at entry to the clinics, (B) determine trends in sexual behaviour and HIV transmission knowledge, (C) determine trends and compare STI/HIV prevalence and (D) describe sociodemographic determinants for STI/HIV infection, over a period of 8 years using data from sentinel STI clinics in Guatemala.

\section{METHODS}

\section{Study design and data collection}

Annual cross-sectional analysis was performed using opportunistic programmatic data gathered from STI clinics in the UALE project, in collaboration with the Guatemalan Ministry of Health and the NGO Fundació Sida $i$ Societat. STI clinic attendees were recruited from January 2005 to December 2012. Sociodemographic, biological, behavioural and HIV transmission knowledge data were collected at baseline registration and during consecutive visits. The study was conducted in three STI clinics located in the municipalities of Santa Lucía Cotzumalguapa, Puerto de San José and Escuintla, in the department of Escuintla. All clinics offered uninterrupted HIV and STI counselling and testing on a voluntary and anonymous basis from 07:00 to 15:00. After obtaining written informed consent from participants, trained health educators conducted pretest HIV counselling and collected data on sociodemographic characteristics and sexual behaviours by means of a structured questionnaire. Subsequently, a medical doctor performed a complete clinical examination, as described elsewhere. ${ }^{9}$ Follow-up visits were performed on a 6-month basis, although a drop-in service was available on request. Samples were collected by a nurse practitioner who also performed both the HIV and syphilis testing by finger prick. Blood was drawn by venepuncture from participants with a reactive HIV or positive syphilis rapid test result; participants were counselled posttest and asked to return to the STI clinic after 7 days to receive their confirmatory test result. Subjects with an HIV positive confirmatory test were referred and accompanied by a community health worker to the HIV referral hospital for enrolment in the HIV care and treatment programme. STI treatment was provided for those patients with positive results according to national guidelines.

All analytical tests were performed at the Escuintla STI clinic microbiology laboratory following national standard operating procedures as previously described. ${ }^{9}$ The presence of Trichomona vaginalis and yeasts were examined by wet mount preparation microscopy of secretions collected from the posterior vaginal fornix. An endocervical swab was tested by enzyme immunoassay (Chlamydia Ag Card; Ulti med products, GmbH, Ahrensburg, Germany) to detect Chlamydia trachomatis. A second endocervical swab was cultured on modified Thayer-Martin medium for the diagnosis of Neisseria gonorrhoeae. Serologies for syphilis and HIV were performed using rapid tests. For reactive HIV samples, positivity was confirmed by ELISA using Bioelisa HIV-1+2 (Biokit, Lliçàd'Amunt, Spain). All reactive syphilis samples were further confirmed for diagnosis of active syphilis disease using Treponema pallidum haemagglutination test (Immutrep TPHA; Omega Diagnostics, Alva, UK) and the Venereal Infections Research Laboratory test (VDRL; MurexBiotech Limited, Dartford, UK). Active syphilis was diagnosed when both the VDRL and the TPHA tests were positive, regardless of the VDRL titers and treatment history.

\section{Measures and definitions}

FSW were defined as women who reported having sex in exchange for money during the preceding 12 months. MSM were defined as men who self-identified as homosexuals or who reported having sex with penetration with a same-sex partner during the last 12 months. Those clinic attendees who reported being heterosexual and did not 
self-identified neither as FSW nor MSM were grouped as 'high-risk heterosexuals' (HRH), previously described elsewhere. ${ }^{13}$ 'Regular clients' were defined as those men from which FSW reported having sex in exchange of money more than twice in the last year; 'occasional clients' were defined as those men from which FSW reported having sex in exchange of money once or twice in the last year. HIV transmission-related knowledge was assessed by asking attendees to identify HIV transmission routes as previously defined. ${ }^{9}{ }^{10}$ Prevalence of any STI was defined as the proportion of patients with a positive test for an STI among patients tested for the same STI during one specific year, as previously suggested. ${ }^{4}$ Only the first positive test occurred in any specific year was included, and recurrence of STI other than HIV for any specific year was not considered. Patients were classified as new patients when first attending any of the three STI clinics. Patients attended were defined as any clinic attendee with at least one complete visit in any specific year. Trends in sexual behaviour and HIV transmission knowledge variables were ascertained taking into consideration the answer given in the latest risk questionnaire performed in the specific year.

\section{Data analysis}

Data were anonymised using an alphanumeric unique code for each participant, and analysed using STATA V.12.1 (Stata-Corp, College Station, TX). $\chi^{2}$ Fisher's exact test and $\chi^{2}$ test for linear trends were used in the univariate analysis. Median comparisons were performed using Kruskal-Wallis test. Prevalence trends were studied for HIV, syphilis, gonorrhoea, chlamydia and trichomonas infections. Proportions and adjusted proportion (APr) test for trends were studied for sexual behaviour and HIV transmission knowledge outcomes. Adjusted prevalence ratios (APRs) and APR tests for trends instead of odds ratios were used for HIV and STI prevalence outcomes to increase precision of adjusted estimates and facilitate interpretation of results as previously suggested. ${ }^{1415}$ Poisson regression analysis with robust variance for cluster estimations was used in the multivariable analysis. In the calculations of APR test for trends, year of visit was used as an independent categorical variable. Sociodemographic variables with an association with the outcome of interest with a $p$ value of $<0.20$ in the univariate model were further studied for associations and adjustment for confounding in the multivariable model. The covariables used for adjustment in the multivariable Poisson regression were age, sex, STI clinic origin, having a regular partner, country of birth, education and marital status. The extension of the Mantel-Haenzsel test for trend adjusting for age was used when the Poisson test for linear trend was not of sufficient rank to be performed. Annual and overall HIV and STI prevalence were also compared among transmission groups using $\chi^{2}$ test and residual analysis for multiple comparisons. Complete case analysis was used to handle missing data, and no interaction neither effect modification measures were considered in the multivariable model.
Patient involvement

Within the UALE project pilot implementation phase, patients were asked about their priorities and preferences in order to generate the questionnaires to be used. Prestudy meetings were held with civil society associations to better inform about the research agenda and the outcomes and benefits of the study. Results of the study will be disseminated through the clinics using friendly scientific language and translated into Spanish and Maya.

\section{RESULTS}

A total of 4027 new attendees were registered during the 8-year study period. Of these, $3213(79.78 \%)$ were FSW, 229 (5.69\%) were MSM and 585 (14.53\%) were classified as HRH. There were a total of 8109 visits by 4027 persons. Sixty-one per cent of clinic attendees had a single visit; the remaining 1553 patients had a mean number of 3.6 visits per person (IQR, (2-4) max 14). The peak number of new patients per year occurred in 2008 (646), falling to 301 in 2012. The proportion of follow-up visits increased throughout the project from $16.80 \%$ in 2005 to $61 \%$ in 2012. Majority of HRH (91.10\%) had only a single visit. The proportion of FSW and MSM who had a single visit was $56.42 \%$ and $57.23 \%$, respectively. Sociodemographic characteristics at baseline registration were studied for new patients attending the STI clinics (table 1). FSW have the highest proportion of illiteracy or incomplete primary school education (52.20\%) and the MSM group has the lowest $(19.80 \%)$. Having a regular partner was common in HRH $(69.70 \%)$ and less common in FSW $(29.20 \%)$ and MSM $(27.70 \%)$. HRH is composed mainly of general heterosexual population, partners of FSW, not self-identified FSW and MSM, truck drivers, military staff and immigrants working in the sugar cane industry.

APr linear trends for sexual behaviour and HIV transmission knowledge variables were evaluated for transmission groups (tables 2 and 3 ). In most years, over $95 \%$ of FSW reported condom use in their last sexual intercourse (CLSI) with both regular and occasional clients. However, condom use was lower with their regular partners ranging from $19.60 \%$ in 2006 to $22 \%$ in 2012. For FSW, having unprotected sex as a way to transmit HIV showed proportions over $95 \%$ since 2008. Conversely, vertical transmission knowledge of HIV showed lower proportions, despite an increasing linear trend from $9.20 \%$ in 2006 to $41.30 \%$ in 2010. For MSM, proportions of CLSI with occasional partners ranged from $57.1 \%$ in 2007 to $58.10 \%$ in 2012. The proportion of HRH reporting CLSI with regular partners was lower than 20\%. Furthermore, proportion of CLSI with occasional partners showed a decreasing trend during the study period (from $35 \%$ to $14.30 \%$, respectively).

In table 4, prevalence and prevalence trends were analysed for HIV and STI in clinic attendees. For FSW, a decreasing prevalence trend for HIV, syphilis and chlamydia was observed along the study period. Prevalence of trichomonas decreased from $14 \%$ in 2005 to $9.90 \%$ in 
2009, and since then, an increased prevalence trend was observed (15.50\% in 2012). For MSM, annual HIV and STI prevalence are presented. However, due to sample size limitations, trends could not be estimated. Gonorrhoea prevalence had an unexpected high increase in year 2012 in all transmission groups (FSW: $21.20 \%$, MSM: $35 \%$ and HRH: 25\%). For HRH, prevalence trends of HIV and syphilis could not be estimated due to sample size limitations. Gonorrhoea prevalence trends in HRH did not decrease over time, and HRH also showed an increased prevalence trend in chlamydia and trichomonas infections reaching a peak at the end of the study period in 2012 with prevalence of $13.40 \%$ and $23.90 \%$, respectively.

Annual and overall HIV and STI prevalence were also compared among transmission groups. Globally, for the period 2007-2012, differences were observed in HIV among MSM $(8.17 \%)$ in comparison with FSW $(2.10 \%)$ and HRH $(4.12 \%)$. Differences in gonorrhoea prevalence during the 2007-2012 study period were observed. The highest prevalence was in MSM $(22.76 \%)$, and both MSM and HRH (14.91\%) had higher gonorrhoea prevalence compared with FSW (9.28\%). Overall prevalence for chlamydia in FSW and HRH were $6.80 \%$ and $6.91 \%$, respectively. Overall prevalence for trichomonas in FSW and HRH were $12.26 \%$ and $12.38 \%$, respectively. In table 5, sociodemographic risk factors for STI in clinic attendees were analysed by transmission groups. Sociodemographic risk factors for HIV and STI among FSW were older age and having a limited education level. The risk of chlamydia and trichomonas infections was higher in Guatemalan-born FSW compared with Central American-born FSW. Having a regular partner was a 'protective factor' for gonorrhoea infection in the case of HRH.

\section{DISCUSSION}

Our results present the evolution of HIV/STI prevalence, sexual risk behaviours and HIV transmission knowledge over 8 years of the UALE programme. HIV and syphilis prevalence consistently declined in FSW. The overall HIV prevalence was higher in MSM compared with FSW and HRH. Interestingly, no differences in HIV prevalence between FSW and HRH were observed, as reported previously. ${ }^{13}$ Annual and global HIV, gonorrhoea and chlamydia prevalence in FSW was higher compared with other recent studies ${ }^{16}$ but similar to those reported in HIV national and international reports. ${ }^{6}$ Our results indicate that most STI diagnoses were detected at first visit; in the case of HIV, $78.10 \%$ of all cases detected occurred in patient's baseline visit at the clinics, so the contribution of new patients to the estimated burden of HIV was high. Gonorrhoea prevalence was higher in MSM and HRH compared with FSW. Gonorrhoea prevalence trends did not decline over time in any of the transmission groups studied. The unexpected high increase in year 2012 for all transmission groups could be partly explained by the decline in the activity of 2 of the 3 clinics in years 2011 and 2012, due to funding restrictions that might 
Table 2 Proportions and proportion trends in sexual behaviour and HIV transmission knowledge in FSW attended per year

Sexual behaviour

HIV transmission knowledge

Condom use in last sexual intercourse with:

\begin{tabular}{llllllll}
$\begin{array}{l}\text { Regular } \\
\text { partner }\end{array}$ & Regular client & $\begin{array}{l}\text { Occasional } \\
\text { client }\end{array}$ & $\begin{array}{l}\text { Place of sex } \\
\text { work }\end{array}$ & $\begin{array}{l}\text { Number of } \\
\text { clients in the } \\
\text { last week }\end{array}$ & $\begin{array}{l}\text { By unprotected } \\
\text { sex }\end{array}$ & $\begin{array}{l}\text { Vertical } \\
\text { transmission }\end{array}$ \\
\hline Yes (\%) & Yes (\%) & Yes (\%) & Bar (\%) & $\geq 5$ clients (\%) & Yes (\%) & Yes (\%)
\end{tabular}

FSW

\begin{tabular}{|c|c|c|c|c|c|c|c|}
\hline $\operatorname{ear}\left(n^{\star}\right)$ & & & & & & & \\
\hline $2005(543) \dagger$ & - & - & - & - & - & - & - \\
\hline $2006(507)$ & 19.61 & 93.42 & 96.63 & 97.63 & 34.16 & 90.74 & 9.25 \\
\hline 2007 (755) & 37.78 & 96.73 & 95.79 & 94.35 & 62.11 & 93.67 & 61.64 \\
\hline 2008 (871) & 24.17 & 98.92 & 88.24 & 94.88 & 52.36 & 97.07 & 35.71 \\
\hline 2009 (854) & 22.51 & 94.98 & 82.16 & 92.03 & 53.64 & 98.57 & 31.67 \\
\hline 2010 (837) & 20.95 & 96.90 & 95.45 & 91.50 & 51.20 & 98.66 & 41.29 \\
\hline 2011 (735) & 29.41 & 96.19 & 97.79 & 87.95 & 49.18 & 99.03 & - \\
\hline 2012 (525) & 21.99 & 95.13 & 97.14 & 89.67 & 47.98 & 99.03 & - \\
\hline $\begin{array}{l}\text { APr test for } \\
\text { trend } \neq\end{array}$ & $\begin{array}{l}0.95 \\
(0.90 \text { to } 0.99)\end{array}$ & $\begin{array}{l}1 \\
\text { (0.99 to } 1)\end{array}$ & $\begin{array}{l}1.01 \\
\text { (1 to } 1.01 \text { ) }\end{array}$ & $\begin{array}{l}0.98 \\
(0.98 \text { to } 0.99)\end{array}$ & $\begin{array}{l}0.99 \\
\text { (0.98 to } 1.01)\end{array}$ & $\begin{array}{l}1.02 \\
\text { (1.02 to } 1.03)\end{array}$ & $\begin{array}{l}1.21 \\
\text { (1.18 to } 1.24)\end{array}$ \\
\hline $\mathrm{P}$ values & 0.029 & 0.887 & $<0.0001$ & $<0.0001$ & 0.863 & $<0.0001$ & $<0.0001$ \\
\hline $\begin{array}{l}\text { Variable missing } \\
\text { data (\%) }\end{array}$ & 10.12 & 21.22 & 9.69 & 1.21 & 2.65 & $<0.50$ & 1.10 \\
\hline
\end{tabular}

${ }^{*}$ Sample size of FSW attended in the specific year.

†The sexual behaviour questionnaire was not fully implemented in 2005.

$\ddagger$ Adjusted proportion (APr) test for trend with $95 \% \mathrm{Cl}$ using a Poisson binomial model with year as an ordered categorical variable adjusted for sociodemographic variables with a $\mathrm{p}$ value $<0.2$ in the univariate test, (age, sex, STI clinic origin, having a regular partner, country of birth, education and marital status).

FSW, female sex workers.

have caused a cumulative effect of patients attending the remaining STI clinic. Increasing prevalence trends in chlamydia and trichomonas infections were observed in HRH that might be also partly explained for the decline in STI clinics activities. However, the true disease burden of gonorrhoea and chlamydia might be underestimated if we take into account that only first STI episodes per year were analysed, and therefore, reinfection rates were not studied despite previous reported reinfection rates for gonorrhoea in FSW in the $7 \%-10 \%$ range. Older age and illiteracy or incomplete primary school were sociodemographic risk factors for HIV in FSW as previously reported. ${ }^{13}$ Proportions of CLSI with regular and occasional clients in FSW remained high, mostly over $90 \%$. In contrast, CLSI with regular partners was lower, mainly below $30 \%$, and decreased over time as suggested by others. ${ }^{12}$ Evidence shows that low condom use among FSW is the norm in private life, mainly because it may serve as a psychological distinction between work and private lives and because of feelings of trust and intimacy with regular partners. ${ }^{17}$ Nevertheless, FSW condom use negotiation skills might be influenced either by violence associated with rejecting unprotected sex with regular partners or due to economic pressures during commercial sex with clients as previously suggested. ${ }^{18}{ }^{19} \mathrm{HRH}$ had the lowest proportions and trends of CLSI with regular and occasional partners among transmission groups studied; this is in accordance to previous studies showing that HRH had higher than expected HIV and STI prevalence and sexual risk behaviours. ${ }^{1320} \mathrm{HRH}$ is a difficult group to reach; it is composed mainly of general heterosexual population, partners of FSW, not self-identified FSW and MSM, truck drivers, military staff and immigrants working in the sugar cane industry, among other hard-to-reach populations. Of concern is that HRH might be acting as a bridge population as $17 \%$ of them reported having sex with FSW and multiple partners in previous studies. ${ }^{13}$ The fact that $91 \%$ of HRH attendees had only one visit to the clinics, and most importantly, the fact that prevalence for HIV, chlamydia and trichomonas did not differ among FSW and HRH, makes the characterisation of this group a challenging and worthwhile effort to better understand the driving forces of the HIV/STI epidemiology in Escuintla. FSW, MSM and HRH had suboptimal follow-up rates, as more than $56.40 \%, 57.20 \%$ and $91 \%$ of them, respectively, had only one visit. Adherence to the programme seems to be associated to risk perception, being HRH and FSW the groups with the lowest and highest follow-up rates, respectively. Reasons to explain this fact could rely on stigma and discrimination driving healthcare seeking behaviours. ${ }^{21}$ Structural interventions addressing sexual violence, stigma and discrimination and how they negatively impact health seeking behaviours need to be better identified and targeted for effective behavioural change outcomes. $^{22}{ }^{23}$ HIV transmission knowledge by unprotected sex seems to be well known among all transmission 
Table 3 Proportions and proportion trends in sexual behaviour and HIV transmission knowledge in MSM and HRH attended per year

\begin{tabular}{|c|c|c|c|c|c|}
\hline & \multicolumn{3}{|l|}{ Sexual behaviour } & \multicolumn{2}{|c|}{ HIV transmission knowledge } \\
\hline & \multicolumn{2}{|c|}{$\begin{array}{l}\text { Condom use in last sexual intercourse } \\
\text { with: }\end{array}$} & \multirow[b]{2}{*}{$\begin{array}{l}\text { Age at first sex* } \\
\text { median (IQR) }\end{array}$} & \multirow{2}{*}{$\begin{array}{l}\text { By unprotected } \\
\text { sex } \\
\text { Yes (\%) }\end{array}$} & \multirow{2}{*}{$\begin{array}{l}\text { Vertical } \\
\text { transmission } \\
\text { Yes (\%) }\end{array}$} \\
\hline & $\begin{array}{l}\text { Regular partner } \\
\text { Yes (\%) }\end{array}$ & $\begin{array}{l}\text { Occasional partner } \\
\text { Yes (\%) }\end{array}$ & & & \\
\hline \multicolumn{6}{|l|}{ MSM†‡ } \\
\hline \multicolumn{6}{|l|}{ Year (n§) } \\
\hline 2007 (16) & - & 57.14 & $10(9-13)$ & 93.75 & 62.50 \\
\hline 2008 (59) & - & 78.38 & $12(11-15)$ & 100 & 42.37 \\
\hline $2009(87)$ & - & 57.14 & $12(12-15)$ & 97.70 & 13.95 \\
\hline $2010(83)$ & - & 62.50 & $13(12-15)$ & 97.60 & 37.35 \\
\hline $2011(77)$ & - & 76.09 & $12(14-15)$ & 100 & - \\
\hline $2012(57)$ & - & 58.06 & $11(14-15)$ & 100 & - \\
\hline APr test for trend & - & $0.96(0.79 \text { to } 1.18)^{\star \star}$ & NAt† & 1 (1 to 1.01$)$ & 0.95 (0.81 to 1.12 ) \\
\hline$P$ value & NA†† & 0.733 & 0.013 & 0.187 & 0.584 \\
\hline $\begin{array}{l}\text { Variable missing } \\
\text { data }(\%)\end{array}$ & - & 8.53 & 5.80 & $<0.5$ & $<0.5$ \\
\hline \multicolumn{6}{|l|}{$\mathrm{HRH}+$} \\
\hline \multicolumn{6}{|l|}{ Year (n§) } \\
\hline 2007 (111) & 13.84 & 35 & $15(14-17)$ & 90.90 & 69.10 \\
\hline 2008 (123) & 13.33 & 37.93 & $16(14-17)$ & 95.04 & 58.68 \\
\hline 2009 (142) & 14.11 & 36.58 & $15(14-17)$ & 93.62 & 70.92 \\
\hline $2010(87)$ & 9.52 & 37.50 & $16(14-17)$ & 93.90 & 64.63 \\
\hline 2011 (72) & 8 & 14.28 & $15(13-16)$ & 97.22 & - \\
\hline $2012(66)$ & 18.60 & 14.28 & $16(14-17)$ & 100 & - \\
\hline APr test for trend ${ }^{*}$ & 0.94 (0.88 to 0.99$)$ & 0.79 (0.63 to 0.98$)$ १ & NA†† & 1 (0.99 to 1.01$)$ & 0.91 (0.83 to 1$)$ \\
\hline$P$ value & 0.042 & 0.033 & 0.345 & 0.187 & 0.056 \\
\hline $\begin{array}{l}\text { Variable missing } \\
\text { data }(\%)\end{array}$ & 14.06 & 22.95 & $<0.5$ & $<0.5$ & $<0.5$ \\
\hline
\end{tabular}

§Sample size of MSM and HRH attended in the specific year.

${ }^{*}$ Sex with penetration.

†The sexual behaviour questionnaire was not fully implemented in years 2005-2006.

$\ddagger$ Sexual behaviour data are from last male partner either occasional or regular.

ๆAdjusted proportion (APr) test for trend with $95 \% \mathrm{Cl}$ using a Poisson binomial model with year as an ordered categorical variable and adjusted for those sociodemographic variables with a $\mathrm{p}$ value $<0.2$ in the univariate test (age, sex, STI clinic origin, having a regular partner, country of birth, education and marital status).

** Mantel-Haenszel extension for linear trend adjusted for age was used when the Poisson model test for clustered data was not of sufficient rank to be performed.

††Not applicable.

$\mathrm{HRH}$, high-risk heterosexuals; MSM, men who have sex with men; STI, sexually transmitted infections.

groups studied. However, a community-based intervention may be necessary to educate about vertical transmission of HIV, which seems to be known as a lesser extent. Recent studies show the effectiveness in increasing testing coverage for HIV and syphilis in rural areas using outreach interventions. ${ }^{24}$ Unfortunately, our HIV transmission knowledge results are aligned with recent data suggesting that Guatemala has one of the lowest percentages of antiretroviral coverage in pregnant women, and thus altogether suggests that vertical transmission of HIV is still a big concern. ${ }^{3}$

\section{Limitations}

Selection bias may affect external validity if those FSW, MSM or HRH attending the clinics differ from those not attending the clinics, and therefore, different from those FSW, MSM and HRH in the area served by the clinics. Possible reasons could be that FWS, MSM and HRH with less economic resources might be more likely to attend free-of-charge STI clinics than those with more resources who might attend private health centres to avoid potential stigmatisation. Sexual behaviour indicators reporting CLSI may not adequately represent condom use dynamics. We 

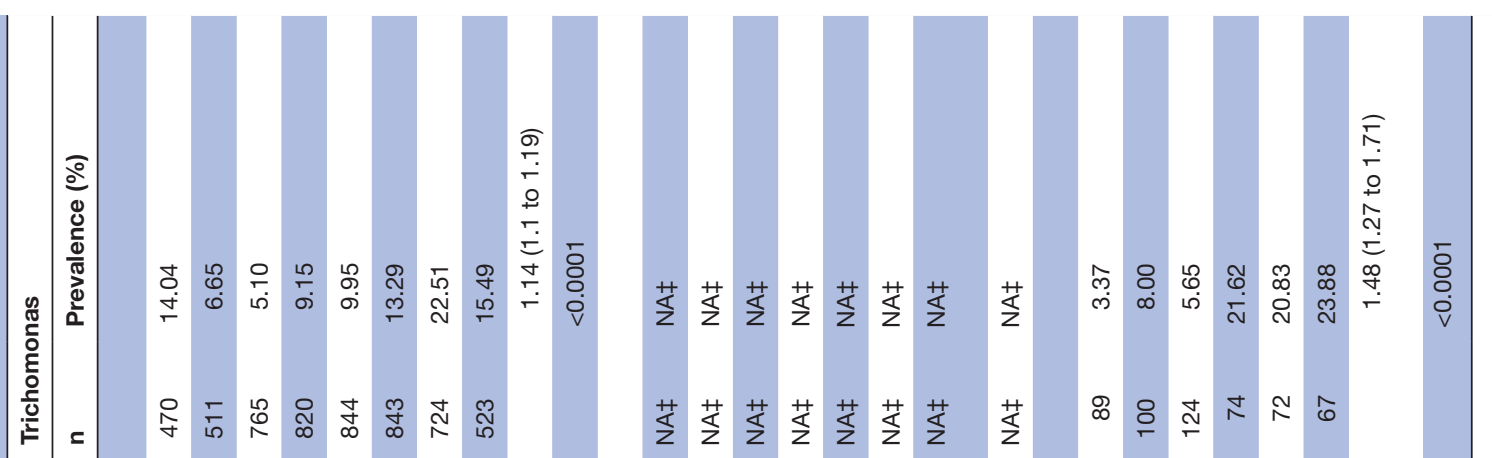

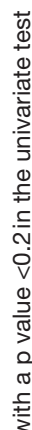

$\underset{c}{\underline{c}}$
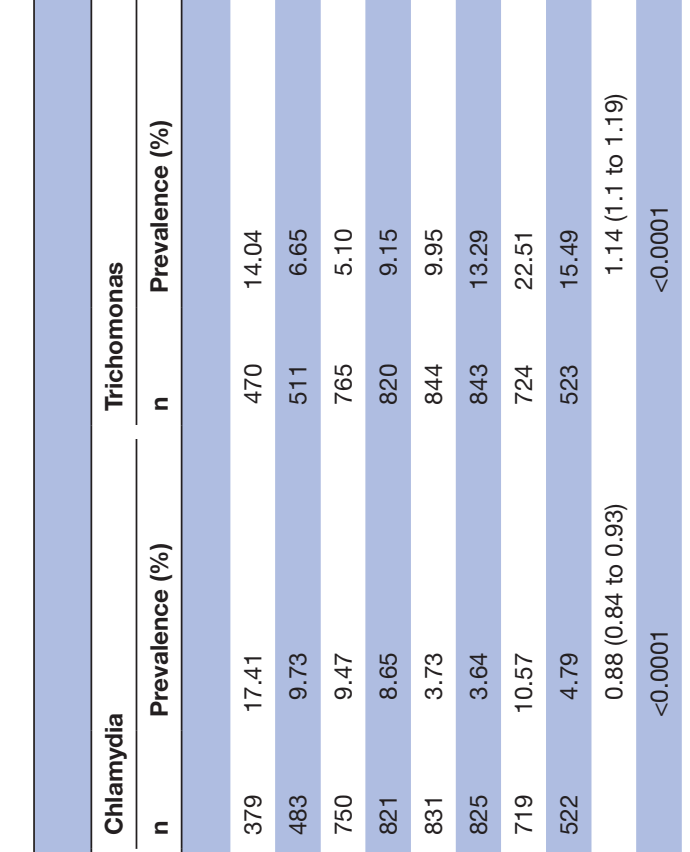

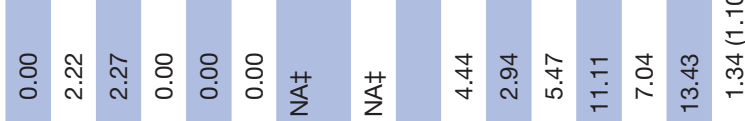

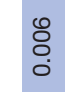

m

৪ ํํำ

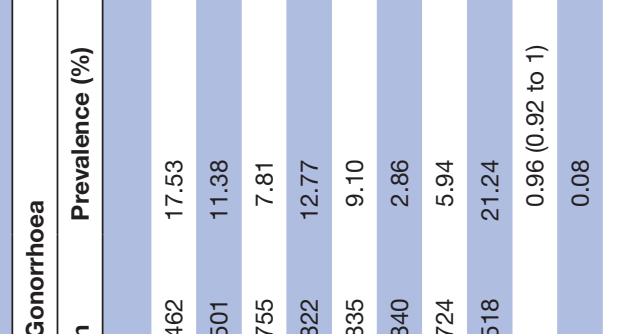

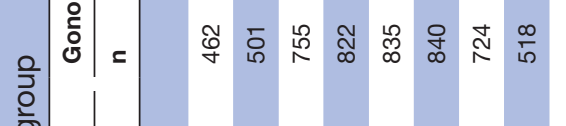

$$
\simeq \text { 요용ㅇㅇ }
$$

$$
\text { ஜ }
$$

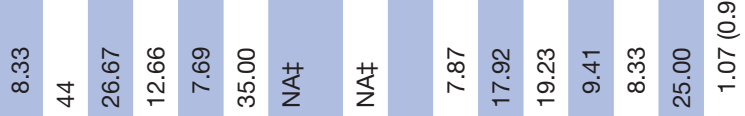

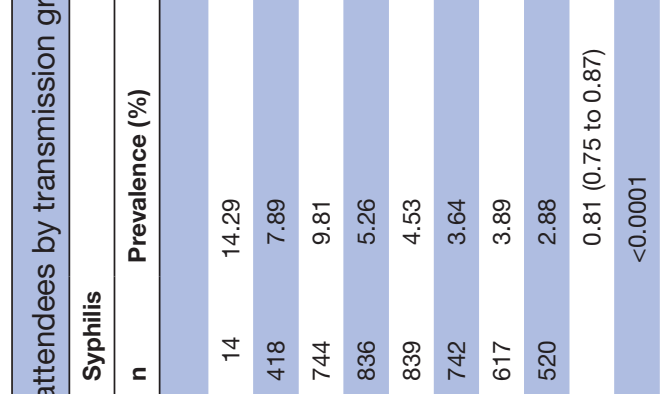

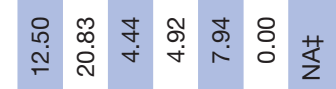

芒

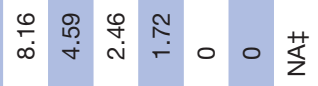

$\because \stackrel{\circ}{\circ}$ ৪

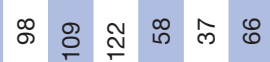

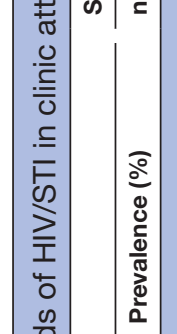

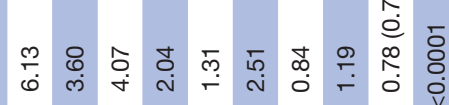

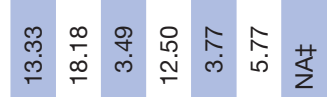

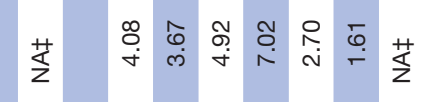

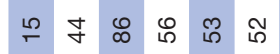

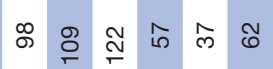

\section{主= 侻}

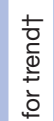

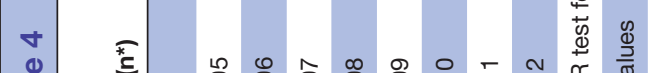

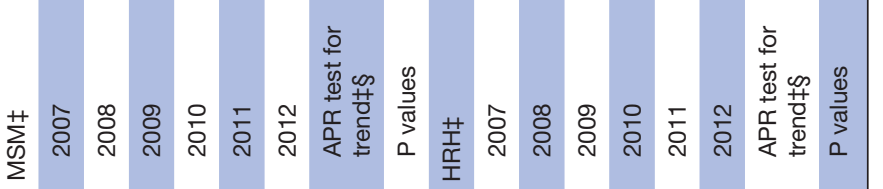


Table 5 Sociodemographic risk factors for HIV/STI by transmission group

\begin{tabular}{|c|c|c|c|c|c|}
\hline $\begin{array}{l}\text { Transmission } \\
\text { group }\end{array}$ & HIV/STI & & & & \\
\hline & & & & APR $(95 \% \mathrm{Cl})^{*}$ & $P$ values \\
\hline \multirow{6}{*}{ FSW } & & & $>30$ & 1.86 (1.30 to 2.65$)$ & 0.001 \\
\hline & & Education & Superior & 1 & - \\
\hline & & & $>30$ & 1.86 (1.46 to 2.37$)$ & $<0.0001$ \\
\hline & Chlamydia & Education & Superior & 1 & - \\
\hline & & & Illiterate or incomplete primary school & 1.27 (1.05 to 1.55$)$ & 0.016 \\
\hline & & Country of birth & Other Central American country & 1 & - \\
\hline \multirow[t]{2}{*}{ MSM } & Syphilis & Having a regular partner & Yes & 1 & - \\
\hline & & & No & $3.90(1.28$ to 11.76$)$ & 0.016 \\
\hline \multirow[t]{2}{*}{$\mathrm{HRH}$} & Gonorrhoea & Having a regular partner & Yes & 1 & - \\
\hline & & & No & 1.64 (1.07 to 2.50$)$ & 0.022 \\
\hline
\end{tabular}

${ }^{*}$ Adjusted prevalence ratio (APR) test with $95 \% \mathrm{Cl}$ using a Poisson binomial model with year as an ordered categorical variable and adjusted for sociodemographic variables with a $\mathrm{p}$ value $<0.2$ in the univariate test, (age, sex, STI clinic origin, having aregular partner, country of birth, education and marital status).

FSW, female sex workers; HRH, high-risk heterosexuals; MSM, men who has sex with men; STI, sexually transmitted infections

also observed potential data discrepancies between STI prevalence trends and condom use data obtained; these discrepancies could be partly explained by self-reporting information bias in clinic attendees. Moreover, high proportions of missing data observed in some sexual behaviour variables might also affect accurate interpretation of data. Prevalence trends in MSM and HRH were not analysed due to sample size limitations, and trends in sexual behaviour should be interpreted with caution. Syphilis results in MSM and HRH for years 2011 and 2012 might be not accurate as sample size was small and previous positive patients might not had been tested again. Further research is needed to accurately describe MSM and HRH sexual behaviour and HIV and STI prevalence data.

\section{CONCLUSIONS}

This is one of the largest clinical datasets for FSW and MSM collected in Guatemala. The multicomponent interventions implemented by the UALE programme are characterised as employing the principles of a combination prevention model to reduce the burden of HIV and STI. Evidence from additional studies within the UALE programme support its effectiveness in prevention and control of HIV/STI and the usefulness of integrated biological and behavioural surveillance and integral care management of HIV/STI. ${ }^{24-26}$ In FSW, HIV, syphilis and chlamydia prevalence declines were observed, and proportions of CLSI with regular and occasional clients above $90 \%$ were also observed, despite lower proportions with regular partners. However, MSM and HRH need to be targeted more effectively with behaviour change communication to decrease HIV and STI prevalence, along with improved healthcare access and retention in care. HRH is a difficult group to target with low follow-up rates and high potential to act as a bridge population. A deeper analysis of the multifactorial risk relationships between subpopulations with high risk of HIV and STI and HRH is needed to identify uncovered bridging connections. Continued interventions to engage civil society, NGO, police/military and bar owners with information, education and communication of HIV/STI are critical to reduce stigma and discrimination. ${ }^{25} 27$ Lack of funds to continue providing integral HIV/STI care in target groups in clinical settings might diminish prevention and control strategies in a high prevalent region for HIV and STI and affect the quality of programmatic data for surveillance purposes. ${ }^{26}$

\section{Author affiliations}

${ }^{1}$ Fundació Sida i Societat, Technical Advisor Unit (UAT), Hospital Nacional de Escuintla, Escuintla, Guatemala

${ }^{2}$ Center for Epidemiological Studies on HIV/AIDS and STI of Catalonia (CEEISCAT), Generalitat de Catalunya, Badalona, Spain

${ }^{3}$ Department of Paediatrics, Obstetrics and Gynaecology, Preventive Medicine, and Public Health. PhD Programme in Methodology of Biomedical Research and Public Health., Univeristat Autònoma de Barcelona, Barcelona, Spain

${ }^{4}$ TransLab, Department of Medical Sciences, Universitat de Girona, Girona, Spain ${ }^{5}$ CIBER Epidemiología y Salud Pública, Madrid, Spain

${ }^{6}$ Texas Biomedical Research Institute, San Antonio, Texas, USA 
${ }^{7}$ Department of Internal Medicine, Division of Infectious Diseases. The Ohio State University, Columbus, Ohio, USA

${ }^{8}$ TB Section, National Infection Service, Public Health England, London, UK ${ }^{9}$ Department of Paediatrics, Obstetrics and Gynaecology, Preventive Medicine and Public Health, Univeristat Autonoma de Barcelona, Barcelona, Spain

Acknowledgements We want to thank the strong commitment and hard dedication of all members of the UALE project in Escuintla department. We sincerely thank all patients involved in the study for their commitment in their own health and for helping others through the dissemination of research outcomes to public health policy makers.

Collaborators Anabela Batres, Luis A. Prieto, Elva Orellana, Irma Mazariegos, Leónidas Mazariegos, Maria Izabel Marientos, Carlos Rodenas, Hugo Felipe, Luis Menéndez, Álvaro Peralta, Estuardo Cabrera, Kristian Villavicencio, Manuel Pacheco, Miguel Arturo Meléndez.

Contributors All authors have made substantial contributions to design, analysis and interpretation of data and/or have been involved in drafting and revising the manuscript for important intellectual content and have given final approval of the version to be published. JIG performed the analysis, interpreted data, wrote the manuscript and acted as corresponding author. JC, MS, MN, EC, LA, GH, AS, AC and R0 participated in the study conception and design, supervised development of work and helped in data interpretation and manuscript writing and evaluation. CF, CNJC, JBT and S-HW supervised development of work, helped in data interpretation and manuscript writing and evaluation. All authors have reviewed and accepted the last version of the manuscript.

Funding This work was supported by the Catalan Agency for Development (ACCD), the Spanish Agency for International Development Cooperation (AECID), the City Hall of Barcelona, The Global fund to fight AIDS, Tuberculosis and Malaria, The United States Agency for International Development, through PASCA (USAID/PASCA), and by FSiS.

Competing interests None declared.

Patient consent Not required.

Ethics approval This analysis was included in the general Institutional Review Board of the UALE Project, which was approved by the Hospital Germans Trias I Pujol ethics review committee, and the Escuintla Department of Health with the protocol study number E0-06-007.

Provenance and peer review Not commissioned; externally peer reviewed.

Data sharing statement Due to the sensitive nature of the questions asked in this study, survey respondents were assured raw data would remain confidential and would not be shared.

Open access This is an open access article distributed in accordance with the Creative Commons Attribution Non Commercial (CC BY-NC 4.0) license, which permits others to distribute, remix, adapt, build upon this work non-commercially, and license their derivative works on different terms, provided the original work is properly cited, appropriate credit is given, any changes made indicated, and the use is non-commercial. See: http://creativecommons.org/licenses/by-nc/4.0/.

\section{REFERENCES}

1. Mayaud P, Mabey D. Approaches to the control of sexually transmitted infections in developing countries: old problems and modern challenges. Sex Transm Infect 2004;80:174-82.

2. Mayaud P, McCormick D. Interventions against sexually transmitted infections (STI) to prevent HIV infection. Br Med Bull 2001;58:129-53.

3. García PJ, Bayer A, Cárcamo CP. The changing face of HIV in Latin America and the Caribbean. Curr HIVIAIDS Rep 2014;11:146-57.

4. Soto RJ, Ghee AE, Nunez CA, et al. Sentinel surveillance of sexually transmitted infections/HIV and risk behaviors in vulnerable populations in 5 Central American countries. J Acquir Immune Defic Syndr 2007;46:101-11.

5. García JI, Samayoa B, Sabidó M, et al. The MANGUA project: a population-based HIV cohort in Guatemala. AIDS Res Treat 2015;2015:1-8

6. Ministerio de Salud Pública y Asistencia Social de Guatemala. Informe Nacional sobre los Progresos Realizados en la Lucha Contra el VIH y sida, 2014:127.
7. MASPAS CDC-CAR/DGHA C-U. Encuesta centroamericana de vigilancia de comportamiento sexual y Prevalencia del VIH e ITS en poblaciones vulnerablesy en poblaciones clave (ECVC). Guatemala City: Capítulo Guatemala, 2013.

8. Ghys PD, Diallo MO, Ettiègne-Traoré V, et al. Effect of interventions to control sexually transmitted disease on the incidence of HIV infection in female sex workers. AIDS 2001;15:1421-31.

9. Alary M, Mukenge-Tshibaka L, Bernier F, et al. Decline in the prevalence of HIV and sexually transmitted diseases among female sex workers in Cotonou, Benin, 1993-1999. AIDS 2002;16:463-70.

10. Béhanzin L, Diabaté S, Minani I, et al. Decline in the prevalence of HIV and sexually transmitted infections among female sex workers in Benin over 15 years of targeted interventions. J Acquir Immune Defic Syndr 2013:63:126-34.

11. UNAIDS/WHO Working Group on Global HIV/AIDS and STI Surveillance. Guidelines for second generation HIV surveillance, 2000.

12. Sabidó M, Giardina F, Hernández G, et al. The UALE Project: decline in the incidence of HIV and sexually transmitted infections and increase in the use of condoms among sex workers in Guatemala. J Acquir Immune Defic Syndr 2009;51(Suppl 1):S35-S41.

13. Lahuerta M, Sabidó M, Giardina F, et al. Comparison of users of an $\mathrm{HIV} /$ syphilis screening community-based mobile van and traditional voluntary counselling and testing sites in Guatemala. Sex Transm Infect 2011;87:136-40.

14. Barros AJ, Hirakata VN. Alternatives for logistic regression in crosssectional studies: an empirical comparison of models that directly estimate the prevalence ratio. BMC Med Res Methodol 2003;3:21.

15. de Coul EL, Warning TD, Koedijk FD. Sexual behaviour and sexually transmitted infections in sexually transmitted infection clinic attendees in the Netherlands, 2007-2011. Int J STD AIDS 2014;25:40-51.

16. Morales-Miranda S, Jacobson JO, Loya-Montiel I, et al. Scale-up, retention and HIV/STI prevalence trends among female sex workers attending VICITS clinics in Guatemala. PLoS One 2014;9:e103455.

17. Lazar C, Sanclemente C, Ferrer L, et al. Condom use among female sex workers in Catalonia: why do they use a condom, why don't they use it? AIDS Educ Prev 2015;27:180-93.

18. Urada LA, Morisky DE, Pimentel-Simbulan N, et al. Condom negotiations among female sex workers in the Philippines: environmental influences. PLoS One 2012;7:e33282.

19. Beattie TS, Isac $S$, Bhattacharjee $P$, et al. Reducing violence and increasing condom use in the intimate partnerships of female sex workers: study protocol for Samvedana Plus, a cluster randomised controlled trial in Karnataka state, south India. BMC Public Health 2016;16:660.

20. Niccolai LM, Odinokova VA, Safiullina LZ, et al. Clients of streetbased female sex workers and potential bridging of HIV/STI in Russia: results of a pilot study. AIDS Care 2012;24:665-72.

21. Lahuerta M, Torrens M, Sabidó M, et al. Sexual risk behaviours and barriers to HIV testing among clients of female sex workers in Guatemala: a qualitative study. Cult Health Sex 2013;15:759-73.

22. Vu L, Nieto-Andrade B, DiVincenzo A, et al. Effectiveness of behavior change communications for reducing transmission risks among people living with HIV in 6 countries in central America. AIDS Behav 2015;19:1203-13.

23. Ikeda JM, Racancoj O, Page K, et al. Risk behaviors and perceptions among self-identified men who have sex with men (MSM), bisexuals, transvestites and transgender women in Western Guatemala.

24. Smith A, Sabidó M, Camey E, et al. Lessons learned from integrating simultaneous triple point-of-care screening for syphilis, hepatitis $B$, and HIV in prenatal services through rural outreach teams in Guatemala. Int J Gynaecol Obstet 2015;130(Suppl 1):S70-2.

25. Porras C, Sabidó M, Fernández-Dávila P, et al. Reproductive health and healthcare among sex workers in Escuintla, Guatemala. Cult Health Sex 2008:10:529-38.

26. Barczyk J, García J, Casabona J. The potential contribution of small-scale intervention projects in the field to the national health information system for HIV and sexually transmitted infections: a case study of a multilevel intervention in Guatemala. Int J Public Health 2010;55:693-9.

27. Rocha-Jiménez T, Brouwer KC, Silverman JG, et al. Exploring the context and implementation of public health regulations governing sex work: a qualitative study with migrant sex workers in Guatemala. $J$ Immigr Minor Health 2017;19:1235-44. 